\title{
Integrated pulmonary index can predict respiratory compromise in high-risk patients in the post-anesthesia care unit: a prospective, observational study
}

Yasutoshi Kuroe $^{1 *}$, Yuko Mihara', Shuji Okahara ${ }^{1}$, Kenzo Ishii ${ }^{2}$, Tomoyuki Kanazawa ${ }^{3}$ and Hiroshi Morimatsu ${ }^{1}$

\begin{abstract}
Background: Respiratory compromise (RC) including hypoxia and hypoventilation is likely to be missed in the postoperative period. Integrated pulmonary index (IPI) is a comprehensive respiratory parameter evaluating ventilation and oxygenation. It is calculated from four parameters: end-tidal carbon dioxide, respiratory rate, oxygen saturation measured by pulse oximetry $\left(\mathrm{SpO}_{2}\right)$, and pulse rate. We hypothesized that IPI monitoring can help predict the occurrence of RC in patients at high-risk of hypoventilation in post-anesthesia care units (PACUs).

Methods: This prospective observational study was conducted in two centers and included older adults ( $\geq 75$-yearold) or obese (body mass index $\geq 28$ ) patients who were at high-risk of hypoventilation. Monitoring was started on admission to the PACU after elective surgery under general anesthesia. We investigated the onset of RC defined as respiratory events with prolonged stay in the PACU or transfer to the intensive care units; airway narrowing, hypoxemia, hypercapnia, wheezing, apnea, and any other events that were judged to require interventions. We evaluated the relationship between several initial parameters in the PACU and the occurrence of RC. Additionally, we analyzed the relationship between IPI fluctuation during PACU stay and the occurrences of RC using individual standard deviations of the IPI every five minutes (IPI-SDs).
\end{abstract}

Results: In total, 288 patients were included (199 elderly, 66 obese, and 23 elderly and obese). Among them, 18 patients (6.3\%) developed RC. The initial IPI and $\mathrm{SpO}_{2}$ values in the PACU in the RC group were significantly lower than those in the non-RC group ( $6.7 \pm 2.5$ vs. $9.0 \pm 1.3, p<0.001$ and $95.9 \pm 4.2 \%$ vs. $98.3 \pm 1.9 \%, p=0.040$, respectively). We used the area under the receiver operating characteristic curves (AUC) to evaluate their ability to predict RC. The AUCs of the IPI and $\mathrm{SpO}_{2}$ were $0.80(0.69-0.91)$ and $0.64(0.48-0.80)$, respectively. The IPI-SD, evaluating fluctuation, was significantly greater in the RC group than in the non-RC group (1.47 \pm 0.74 vs. $0.93 \pm 0.74, p=0.002)$.

Conclusions: Our study showed that low value of the initial IPI and the fluctuating IPI after admission to the PACU predict the occurrence of RC. The IPI might be useful for respiratory monitoring in PACUs and ICUs after general anesthesia.

Keywords: Integrated pulmonary index, Respiratory compromise, Post-anesthesia care unit

\footnotetext{
* Correspondence: yasutoman@gmail.com

'Department of Anesthesiology and Resuscitology, Graduate School of

Medicine, Dentistry, and Pharmaceutical Sciences, Okayama University, 2-5-1

Shikata-cho, 700-8558 Kitaku, Okayama, Japan

Full list of author information is available at the end of the article
}

C C The Author(s). 2021 Open Access This article is licensed under a Creative Commons Attribution 4.0 International License, which permits use, sharing, adaptation, distribution and reproduction in any medium or format, as long as you give appropriate credit to the original author(s) and the source, provide a link to the Creative Commons licence, and indicate if changes were made. The images or other third party material in this article are included in the article's Creative Commons licence, unless indicated otherwise in a credit line to the material. If material is not included in the article's Creative Commons licence and your intended use is not permitted by statutory regulation or exceeds the permitted use, you will need to obtain permission directly from the copyright holder. To view a copy of this licence, visit http://creativecommons.org/licenses/by/4.0/ The Creative Commons Public Domain Dedication waiver (http://creativecommons.org/publicdomain/zero/1.0/) applies to the data made available in this article, unless otherwise stated in a credit line to the data. 


\section{Background}

Postoperative pulmonary complications are common and crucial events because they significantly increase the morbidity, mortality, the lengths of intensive care unit and hospital stay, and the healthcare costs [1-3]. Particularly in the post-anesthesia care unit (PACU), severe and preventable respiratory events may occur frequently $[4,5]$; these events were defined as respiratory compromise (RC) [6]. Thus, it is important to predict and prevent these events in PACUs to improve patients' outcomes.

To monitor respiration, it is important to monitor oxygenation and ventilation [7]. Currently, respiratory monitoring in PACUs is performed only using oxygen saturation measured by pulse oximetry $\left(\mathrm{SpO}_{2}\right)$. One of the methods for monitoring ventilation is capnography. However, although it has become an integral part of anesthesia in the operating room for more than 30 years, its value beyond these confinements is limited [8].

The integrated pulmonary index (IPI) is a newly developed index for respiratory monitoring. It is calculated automatically from four components using a fuzzy logic model-end tidal carbon dioxide $\left(\mathrm{ETCO}_{2}\right)$, respiratory rate (RR), $\mathrm{SpO}_{2}$, and pulse rate-and evaluated on a 10point scale; scores $\geq 8$ points are within normal range and those $\leq 4$ points suggest requirement of interventions [9]. The IPI algorithm summarizes the state of ventilation and oxygenation at the point in time. Previous studies reported that IPI correlated with respiratory physiological parameters of patients undergoing sedation for surgeries or for colonoscopy $[10,11]$. However, there is limited evidence on its effectiveness and usefulness in other clinical situations including postoperative setting.

The purpose of this study was to evaluate the clinical relevance of the IPI and its relationships with postoperative RC. We hypothesized that the IPI could be useful for predicting $\mathrm{RC}$ in high-risk patients in PACUs.

\section{Methods}

\section{Ethical considerations}

The study was approved by the institutional ethics review boards of both participating hospitals (No. 2135; No. 205). All patients provided written informed consent prior to inclusion in the study. This manuscript adheres to the applicable Strengthening the Reporting of Observational Studies in Epidemiology guidelines [12].

\section{Study design and patients}

This was a prospective, observational, two-center study conducted in the PACUs of Okayama University Hospital and Fukuyama City Hospital in Japan from October 2014 to March 2015.

We enrolled patients who were scheduled for admission to the PACUs after elective surgery under general anesthesia and were at high risk of postoperative hypoventilation. The criteria for high-risk patients were older age ( $\geq 75$-year-old) or obesity (body mass index $\geq 28$ ). The exclusion criteria were as follows: (1) age $<18$ years, (2) ambulatory surgery. Patients undergoing surgery such as craniotomy, thoracotomy, cardiac surgery were scheduled for transfer to intensive care units without admission to PACUs.

We screened eligible patients before surgery and obtained informed consents. After admission to the PACU, patients were monitored using Capnostream ${ }^{\mathrm{m}}$ $20 \mathrm{P}^{\circ}$ (Medtronic, Boulder, CO) for more than $30 \mathrm{~min}$ in addition to the standard monitors, and any respiratory events and interventions were recorded by the PACU nurses. Supplemental oxygen was administered to patients according to the usual standard clinical practice at the institution.

\section{Variables}

Expired gas sampling lines were attached to extubated patients upon admission to the PACU and the initial $\mathrm{ETCO}_{2}, \mathrm{RR}, \mathrm{SpO}_{2}$, pulse rate, and IPI values were recorded. These parameters were measured until patients were transferred out of the PACU using Capnostream ${ }^{\mathrm{mu}}$ $20 \mathrm{P}^{\circ}$. The sampling line of this device features oral and nasal sampling as well as a supplemental oxygen delivery system [13]; it has a small mouth and nose cover to catch exhaled gas and has apertures for oxygen delivery. The device measures the $\mathrm{ETCO}_{2}$ and RR by sampling exhaled gas and the $\mathrm{SpO}_{2}$ and pulse rate by pulse oximetry. Furthermore, the IPI is calculated automatically from four parameters and all values are displayed on a screen. The calculation methods use fuzzy logic inference model based on expert clinical opinions. After the provisional IPI is assigned according to the matrix table of RR and $\mathrm{ETCO}_{2}$, the definite IPI is decided finally adding evaluation of $\mathrm{SpO}_{2}$ and PR. This algorithm was verified by comparison to experts' scoring of clinical scenarios [9].

If RC would occur, anesthesiologists or nurses recorded the time of the occurrence and the details of the RC in the medical records. Patients' characteristics, including age, sex, body mass index, American Society of Anesthesiologists physical status, surgical procedure type, anesthesia time, and surgery time were retrieved from the electronic anesthetic records.

\section{Outcomes}

The primary outcome was the occurrence of $\mathrm{RC}$ in the PACU. We defined RC as any respiratory event resulting in prolonged PACU stay or transfer to the intensive care unit, such as airway narrowing, hypoxemia $\left(\mathrm{SpO}_{2}<92 \%\right)$, hypercapnia (partial pressure of carbon dioxide in arterial blood $\left[\mathrm{PaCO}_{2}\right] .>45 \mathrm{mmHg}$ and $\left.\mathrm{pH}<7.35\right)$, wheezing, apnea, and any other events that were judged to require interventions by anesthesiologists or nurses. To evaluate 
the respiratory status stability, we selected the IPI fluctuations during the stay in the PACU. Specifically, we recorded the IPI values every 5 min within an hour in each patient and evaluated them as standard deviations (SDs) of the IPI (IPI-SDs). After patients were transferred out of the PACU, we extracted the data from the device on a universal serial bus; the day and time, $\mathrm{SpO}_{2}, \mathrm{ETCO}_{2}, \mathrm{RR}$, pulse rate, and IPI. In cases of data loss because the saturation probe or gas sampling cannula had been dislocated, removed, or not connected to the Capnostream ${ }^{\mathrm{Tw}} 20 \mathrm{P}^{\circ}$, the patients were excluded from the analysis. If RC had occurred, we obtained the details from the medical records.

\section{Statistical analysis}

The study population was divided into two groups according to the occurrence of RC: RC group and non-RC group. We compared the initial parameters at admission to the PACU between the two groups using Wilcoxon's rank-sum test to identify the predictors of RC occurrence.

To evaluate the IPI fluctuation after admission to the PACU, we used the individual IPI-SDs of each patient. Next, we calculated the mean IPI-SDs of both groups and compared them using Wilcoxon's rank-sum test.

Data were presented as absolute values (\%), medians (interquartile range), or means \pm SDs. A $p$ value $<0.05$ was considered statistically significant in all analyzes.

\section{Results}

Overall, 4,159 patients underwent surgery under general anesthesia during the study period. Of these, 2,621 patients were admitted to the PACUs. Among them, 291 patients $(11.1 \%)$ fulfilled at least one of the criteria of this study. However, three patients were excluded due to missing data. Consequently, 288 patients (199 elderly, 66 obese, and 23 elderly and obese patients) were included in this study analysis. The baseline demographic and clinical characteristics of the patients are shown in Table 1. The mean age was $74.8 \pm 14.2$ years and the mean body mass index was $25.0 \pm 5.2$. The mean anesthesia time was $169.4 \pm 95.2 \mathrm{~min}$. According to the surgery type, patients undergoing orthopedic (25.7\%), and abdominal (21.2\%) surgery comprised the highest proportion.

\section{Outcomes}

Among the 288 patients, 18 patients $(6.3 \%)$ developed $\mathrm{RC}$ during their PACU stay. The most frequent cause of RC was hypoxia, which occurred in seven patients $(38.9 \%)$. Airway narrowing occurred in three, apnea in three, hypercapnia in one, wheezing in one, and other respiratory events occurred in three patients (Table 2). Most cases of RC occurred within 30 min after admission to the PACU. The incidence of RC was $5.9 \%$ in elderly patients and $9.0 \%$ in obese patients. The length
Table 1 Baseline demographic and clinical characteristics

\begin{tabular}{|c|c|c|c|}
\hline Variables & $\begin{array}{l}\text { Total } \\
(n=288)\end{array}$ & $\begin{array}{l}\text { RC group } \\
(n=18)\end{array}$ & $\begin{array}{l}\text { Non-RC group } \\
(n=270)\end{array}$ \\
\hline Age & $74.8 \pm 14.2$ & $76.3 \pm 11.8$ & $74.6 \pm 14.4$ \\
\hline Sex (Male) (\%) & 43.4 & 44.4 & 43.3 \\
\hline Body mass index & $25.0 \pm 5.2$ & $27.3 \pm 6.5$ & $24.9 \pm 5.1$ \\
\hline ASA-PS & $2[2-3]$ & $2[2-3]$ & $2[2-3]$ \\
\hline Anesthesia time (min) & $169 \pm 95$ & $207 \pm 110$ & $167 \pm 94$ \\
\hline Surgical Time (min) & $121 \pm 82$ & $154 \pm 99$ & $118 \pm 80$ \\
\hline \multicolumn{4}{|l|}{ Type of surgery } \\
\hline Orthopedic & $74(25.7 \%)$ & $4(22.2 \%)$ & $70(25.9 \%)$ \\
\hline Abdominal & $61(21.2 \%)$ & $4(22.2 \%)$ & $57(21.1 \%)$ \\
\hline Urologic & $38(13.2 \%)$ & $2(11.1 \%)$ & $36(13.3 \%)$ \\
\hline Otorhinolaryngologic & $29(10.1 \%)$ & $4(22.2 \%)$ & $25(9.3 \%)$ \\
\hline Breast internal secretion & $28(9.7 \%)$ & $2(11.1 \%)$ & $26(9.6 \%)$ \\
\hline Obstetrics and gynecology & $15(5.2 \%)$ & $1(5.6 \%)$ & $14(5.2 \%)$ \\
\hline Other & $43(14.9 \%)$ & $1(5.6 \%)$ & $42(15.6 \%)$ \\
\hline
\end{tabular}

All values reported as $\mathrm{n}(\%)$, mean \pm standard deviation, or median [interquartile range]

$R C$ respiratory compromise; ASA-PS American Society of Anesthesiologists physical status

of PACU stay of patients with RC was longer than that of patients without RC $(101 \pm 48 \mathrm{~min}$ versus $61 \pm$ 30 min, $p<0.001$ ).

\section{Association between RC and the initial parameters}

The comparison of the initial parameters on admission to the PACU between the $\mathrm{RC}$ and non- $\mathrm{RC}$ groups is presented in Table 3. The mean initial IPI of the RC group was significantly lower than that of the non-RC group $(6.7 \pm 2.5$ versus $9.0 \pm 1.3 ; p<0.001)$. The mean initial $\mathrm{SpO}_{2}$ of the RC group was also significantly lower than that of the non- $\mathrm{RC}$ group $(95.9 \pm 4.2 \%$ versus $98.3 \pm$ $1.9 \% ; p=0.040)$. In contrast, there were no significant differences in the mean $\mathrm{ETCO}_{2}, \mathrm{RR}$, and pulse rate between the two groups.

Following these results, receiver operating characteristic (ROC) curves were generated to calculate the area

Table 2 Types of respiratory compromise

\begin{tabular}{lc}
\hline Respiratory compromise & N (\%) \\
\hline Hypoxemia & $7(38.9)$ \\
Airway narrowing & $3(16.7)$ \\
Apnea & $3(16.7)$ \\
Hypercapnia & $1(5.6)$ \\
Wheezing & $1(5.6)$ \\
Other & $3(16.7)$ \\
- Insufficient expectoration of sputum & $1(5.6)$ \\
- Rapid shallow breathing & $1(5.6)$ \\
- Respiratory alkalosis & $1(5.6)$ \\
\hline
\end{tabular}


Table 3 The relationship between parameters at admission in PACU and the incidence of respiratory compromise

\begin{tabular}{lccc}
\hline Parameters at admission in PACU & RC group & Non-RC group & p-value \\
\hline Integrated pulmonary index & $6.7 \pm 2.5$ & $9.0 \pm 1.3$ & $<0.001$ \\
$\mathrm{SpO}_{2}$ & $95.9 \pm 4.2$ & $98.3 \pm 1.9$ & 0.04 \\
$\mathrm{ETCO}_{2}$ & $37.6 \pm 11.9$ & $38.6 \pm 6.26$ & 0.94 \\
$\mathrm{RR}$ & $14.2 \pm 6.0$ & $13.6 \pm 4.1$ & 0.70 \\
\hline
\end{tabular}

All values reported as mean \pm standard deviation

PACU post-anesthesia care unit; $R C$ respiratory compromise; $\mathrm{SpO}_{2}$ oxyhemoglobin saturation measured by pulse oximetry; $E T C \mathrm{C}_{2}$ end-tidal carbon dioxide; $R R$ respiratory rate

under the curve (AUC) for the significant initial parameters (Fig. 1). The AUCs for the initial IPI and $\mathrm{SpO}_{2}$ were 0.80 (95\% confidence interval [CI]:: 0.69-0.91) and 0.64 (95\% CI: 0.48-0.80), respectively. When the cut-off point of the initial IPI was 7 to predict RC, its sensitivity, specificity, and likelihood ratio were $55.6 \%, 88.5 \%$ and 4.8 , respectively. When the cut-off point of the initial $\mathrm{SpO}_{2}$ was $96 \%$, its sensitivity, specificity, and likelihood ratio were $44.4 \%, 84.1 \%$ and 2.8 , respectively.

\section{IPI fluctuation after admission to the PACU}

In the analysis of IPI fluctuation after admission to the PACU, 20 patients were excluded because of missing data. Figure 2 displays the IPI value trends after admission to the PACU of both groups. In the non-RC group, the IPI values were stable at a high level (8-10 points); however, in the RC group, those values distributed in a relatively wide range (5-9 points). Furthermore, the mean IPI-SD in the RC group was significantly greater than that in the non-RC group $(1.47 \pm 0.74$ versus $0.93 \pm 0.74, p=0.002)$, indicating that the IPI values fluctuated in a higher proportion of patients in the $\mathrm{RC}$ group compared to the non- $\mathrm{RC}$ group.

\section{Discussion}

\section{Key results}

In this study, we investigated whether the IPI can predict $\mathrm{RC}$ in high-risk adult patients after general anesthesia. We determined that $6.3 \%$ of these patients developed $\mathrm{RC}$ and that their stay in PACUs was significantly prolonged. Patients with $\mathrm{RC}$ had lower IPI and $\mathrm{SpO}_{2}$ values on admission to the PACU than patients without RC. The AUCs for the IPI tended to be higher than that for $\mathrm{SpO}_{2}$, but not significant. After admission to the PACUs, the IPI in the RC group had significantly greater fluctuations than that in the non-RC group throughout the PACU stay.

\section{Relationship to previous findings}

The incidence of $\mathrm{RC}$ was $6.3 \%$ in our high-risk patients after surgeries under general anesthesia, except cardiovascular, thoracic, and craniotomy surgeries, which require postoperative intensive care. Several studies have

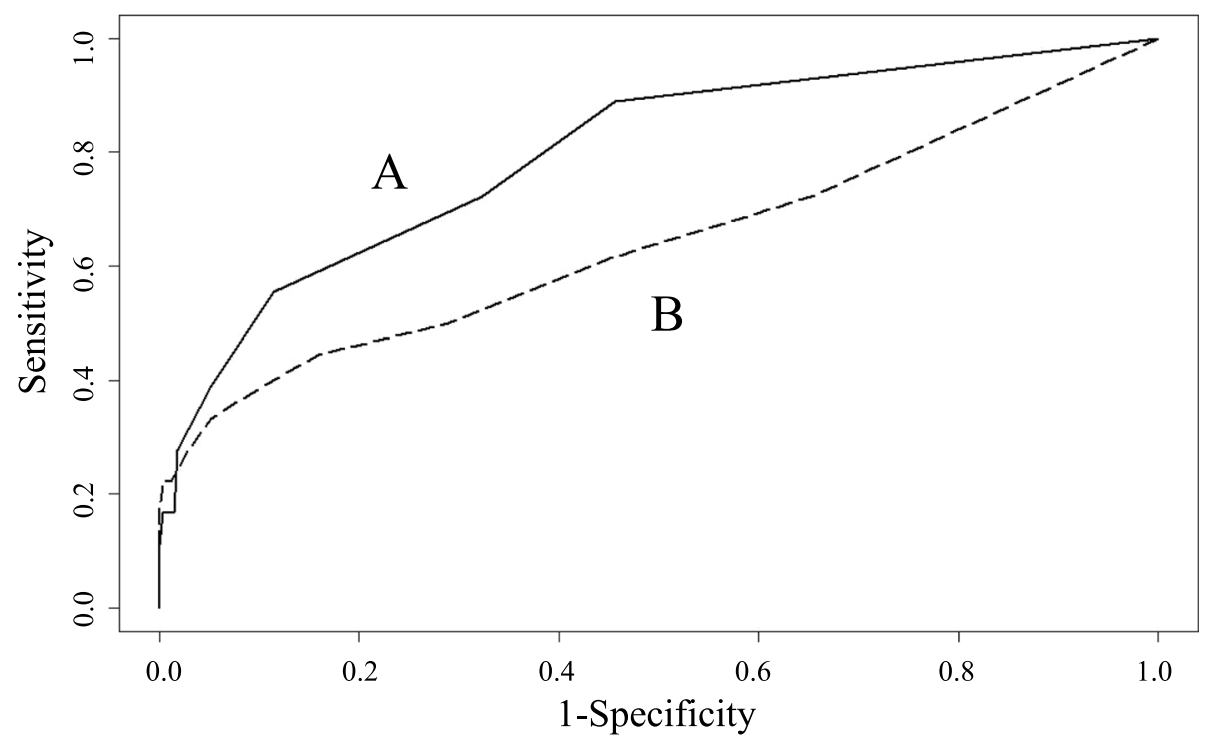

Fig. 1 Predictors of RC in PACUs. Comparisons of the receiver operating characteristic curves for the initial IPI (A) and $S p \mathrm{O}_{2}(B)$ values as predictors of RC in PACUs. The AUCs of the IPI and $\mathrm{SpO}_{2}$ were 0.80 and 0.64 , respectively. RC: respiratory compromise, PACU: post-anesthesia care unit, IPI: integrated pulmonary index, $\mathrm{SpO}_{2}$ : oxyhemoglobin saturation measured by pulse oximetry 


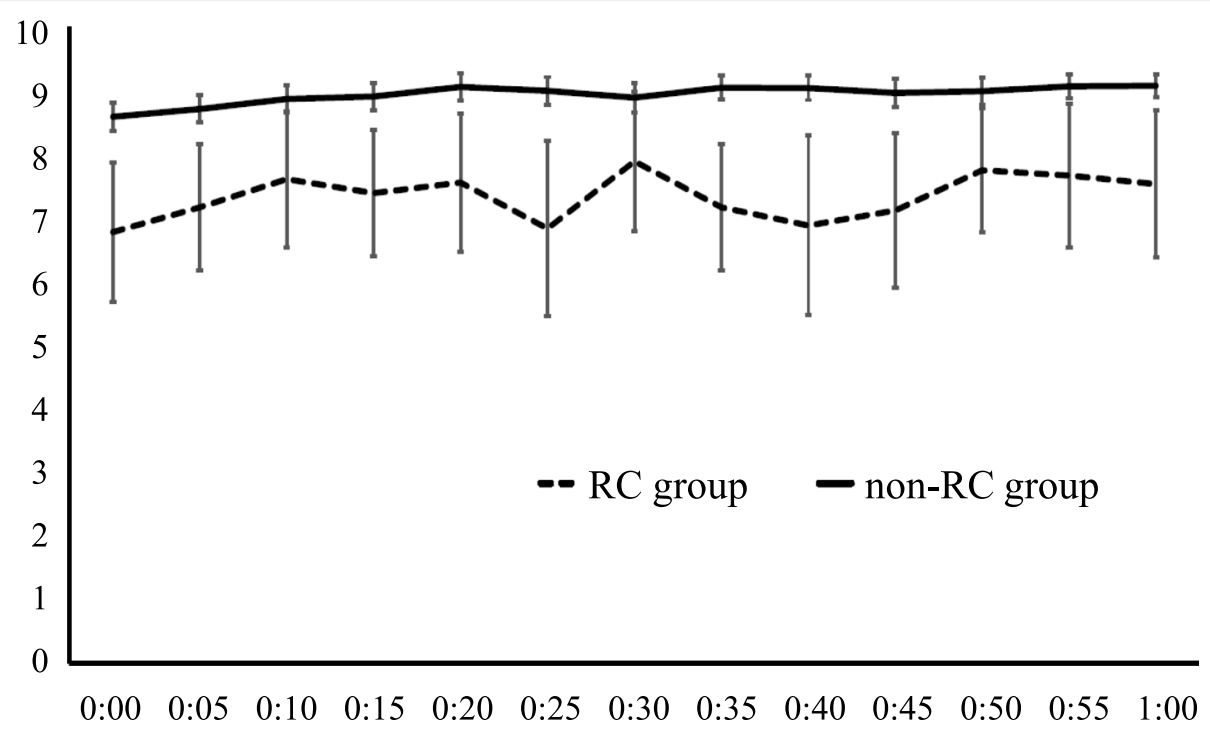

Fig. $2 \mathrm{IPI}$ fluctuation during PACU stay. This graph shows the fluctuation of the IPI values of each group at every $5 \mathrm{~min}$ within $1 \mathrm{~h}$ after admission to the PACU. The means and $95 \% \mathrm{Cls}$ of the IPI values at every point is described on the continuous line and the dashed line connects the mean IPI values for every 5 min. The ends of the upper and lower whiskers represent the $95 \%$ Cls. IPI: integrated pulmonary index, PACU: post-anesthesia care unit, Cl: confidence interval, RC: respiratory compromise

surveyed the incidence of postoperative $\mathrm{RC}$ in the PACU; in these studies, the incidence ranged from 1.3 to $16 \%[4,14,15]$. We attributed the difference with our findings to the difference in the definition of respiratory events and the inclusion criteria among the studies. In our study, we determined the definition of $\mathrm{RC}$ in reference to previous studies and included only high-risk patients [11].

In present study, the initial values of the IPI on admission to the PACU could be a predictor of the occurrence of RC in PACUs. Although we could not show the superiority of the prediction ability of the IPI to that of the $\mathrm{SpO}_{2}$, there are some studies that show the importance of evaluating the ventilation in addition to the oxygenation.

Thomas et al. reported that capnography, but not pulse oximetry, alerted impending respiratory depression in their study including postoperative patients receiving patient-controlled analgesia [16]. Kaur et al. verified on the role of the IPI in identifying extubation failure. The IPI value $1 \mathrm{~h}$ after extubation was significantly lower in the failed extubation group than in the successful extubation group [17]. These reports support the possibility of IPI as a respiratory monitoring tool in the perioperative period including PACU.

Additionally, greater fluctuations of the IPI values could indicate risk of RC. Not only the initial IPI value, but its fluctuations should be monitored as well, as respiratory status instability is a risk for RC. Lynn et al. reported that repetitive reductions in airflow and $\mathrm{SpO}_{2}$ were followed by arousal failure and hypoxic death [7].
However, there has been no study that statistically analyzed the degree of respiratory status fluctuation after general anesthesia. As the perioperative patients' respiratory status can be continuously monitored using capnography in addition to $\mathrm{SpO}_{2}$, it would detect $\mathrm{RC}$ more preciously to follow up the fluctuation of the IPI values.

\section{Clinical implications}

Capnometer is commonly used for intubated patients during surgery, but our study presented that $\mathrm{ETCO}_{2}$ can be measured noninvasively using nasal cannula with sampling line and IPI was evaluable for non-intubated patients. For high-risk patients such as patients with obstructive sleep apnea symptoms, [18] comprehensive oxygenation and ventilation monitoring would enable early recognition and treatment of RC. As IPI classifies patient status on simple 10-point scale ( $\geq 8$ : within normal range and $\leq 4$ : requirement of interventions), it would particularly help junior doctors or co-medical staffs in PACU to grasp respiratory conditions objectively regardless of their experiences and knowledge. Large-scale prospective studies will be required to assess the usefulness of IPI algorithm as an early warning tool under these situations.

\section{Limitations}

The limitations of this study are as follows. First, our study was not blinded. All patients received routine care by the PACU staff, mainly nurses or anesthesiologists, and the staff were not blinded to additional parameters (IPI, $\mathrm{ETCO}_{2}$, and RR) displayed by the Capnostream ${ }^{\text {ma }}$ 
$20 \mathrm{P}^{\circ}$. This could have affected the predictive value of these parameters. However, most of the staff were not familiar with the IPI and we informed only some of the staff members of the related details. Second, the time to the occurrence of $\mathrm{RC}$ was on average only $30 \mathrm{~min}$. However, we can add detailed physiological and laboratory measures with increased nursing ratio or X-ray, if required. Third, we enrolled only patients who were elderly or obese as a high-risk group in this study; hence, our findings cannot be generalized to all patients. Finally, the incidence of RC could have been influenced by our definition. Because there is no clear definition, we determined the definition of $\mathrm{RC}$ referring to previous studies. We believe that the incidence of RC in our study was quite reasonable.

\section{Conclusions}

Our results demonstrated that the IPI can predict the occurrence of RC in high-risk patients in PACUs. Therefore, evaluation of the IPI, including the $\mathrm{SpO}_{2}, \mathrm{RR}$, $\mathrm{ETCO}_{2}$, and pulse rate, might be useful for respiratory monitoring at PACUs and intensive care units after general anesthesia.

\section{Abbreviations \\ AUC: Area under the curve; $\mathrm{Cl}$ : Confidence interval; $\mathrm{ETCO}_{2}$ : End tidal carbon dioxide; IPI: Integrated pulmonary index; IPI-SD: Standard deviation of the IPI every five minutes; $\mathrm{PaCO}_{2}$ : Partial pressure of carbon dioxide in arterial blood; PACU: Post-anesthesia care unit; RC: Respiratory compromise; RR: Respiratory rate; SD: Standard deviation; $\mathrm{SpO}_{2}$ : Oxygen saturation measured by pulse oximetry}

\section{Acknowledgements}

We would like to thank Editage (www.editage.com) for English language editing.

\section{Authors' contributions}

YK helped in study conceptualization (definition of study aim and design), data acquisition and analysis, and interpretation of the results. He drafted the first version of the manuscript and further revised it for intellectual content. YM helped in study conceptualization (definition of study aim and design), data acquisition. SO helped in study conceptualization (definition of study aim and design), data acquisition and analysis, and interpretation of the results, and revised the manuscript for intellectual content. KI helped in study conceptualization (definition of study aim and design), data acquisition and analysis, and interpretation of the results. TK helped with data analysis, interpretation of the results, and revised the manuscript for intellectual content. HM helped in study conceptualization (definition of study aim and design), data analysis, interpretation of the results, and revised the manuscript for intellectual content. All authors have read and approved the final version of the manuscript.

\section{Authors' information (optional)}

Not applicable.

\section{Funding}

This work received no specific funding. The CapnostreamTM 20P® that was used to monitor the integrated pulmonary index value in our study was leased from Covidien Japan Inc.

\section{Availability of data and materials}

The datasets generated and analyzed during the present study are available from the corresponding author on reasonable request.

\section{Declarations}

\section{Ethics approval and consent to participate}

This study was approved by the institutional ethics review boards of Okayama University Hospital and Fukuyama City Hospital (No. 2135; No. 205) All patients provided written informed consent prior to inclusion in the study.

\section{Consent for publication}

All patients provided written consent for publication prior to inclusion in the study.

\section{Competing interests}

None.

\section{Author details}

${ }^{1}$ Department of Anesthesiology and Resuscitology, Graduate School of Medicine, Dentistry, and Pharmaceutical Sciences, Okayama University, 2-5-1 Shikata-cho, 700-8558 Kitaku, Okayama, Japan. ²Department of Anesthesiology and Oncological Pain Medicine, Fukuyama City Hospital, 5-23- 1 Zaocho, 721-8511 Hukuyama, Hiroshima, Japan. ${ }^{3}$ Department of Pediatric Anesthesiology, Okayama University Hospital, 2-5-1 Shikata-cho, 700-8558 Kitaku, Okayama, Japan.

Received: 22 October 2020 Accepted: 9 April 2021

Published online: 21 April 2021

\section{References}

1. Smith PR, Baig MA, Brito V, Bader F, Bergman MI, Alfonso A. Postoperative pulmonary complications after laparotomy. Respiration. 2010;80:269-74.

2. Fisher BW, Majumdar SR, McAlister FA. Predicting pulmonary complications after nonthoracic surgery: A systematic review of blinded studies. Am J Med. 2002;112:219-25.

3. Fleisher LA, Linde-Zwirble WT. Incidence, outcome, and attributable resource use associated with pulmonary and cardiac complications after major small and large bowel procedures. Perioper Med (Lond). 2014;3:7.

4. Hines R, Barash PG, Watrous G, O'Connor T. Complications occurring in the postanesthesia care unit: a survey. Anesth Analg. 1992;74:503-9.

5. Mathew JP, Rosenbaum SH, O'Connor T, Barash PG. Emergency tracheal intubation in the postanesthesia care unit: physician error or patient disease? Anesth Analg. 1990;71:691-7.

6. Morris TA, Gay PC, Maclntyre NR, Hess DR, Hanneman SK, Lamberti JP, et al. $\mathrm{RC}$ as a new paradigm for the care of vulnerable hospitalized patients. Respir Care. 2017;62:497-512.

7. Lynn LA, Curry JP. Patterns of unexpected in-hospital deaths: a root cause analysis. Patient Saf Surg. 2011:5:3.

8. Kodali BS. Capnography outside the operating rooms. Anesthesiology. 2013; 118:192-201.

9. Ronen M, Weissbrod R, Overdyk FJ, Ajizian S. Smart respiratory monitoring: clinical development and validation of the $\mathrm{IP}^{\mathrm{TM}}$ (Integrated Pulmonary Index) algorithm. J Clin Monit Comput. 2017;31(2):435-42.

10. Arzu Yıldııım, Ar. Süheyla Abitağaoğlu, Güldem Turan, Ceren Şanlı Karip, Nur Akgün, Doğa Meriç Boybeyi, Dilek Erdoğan Arı. Integrated Pulmonary Index (IPI) monitorization under sedation in cataract surgery with phacoemulsification technique. Int Ophthalmol. 2019;39(9):1949-54.

11. Berkenstadt H, Ben-Menachem E, Herman A, Dach R. An evaluation of the Integrated Pulmonary Index (IPI) for the detection of respiratory events in sedated patients undergoing colonoscopy. J Clin Monit Comput. 2012;26(3): 177-81.

12. von Elm E, Altman DG, Egger M, Pocock SJ, Gøtzsche PC, Vandenbroucke JP, STROBE Initiative. The Strengthening the Reporting of Observational Studies in Epidemiology (STROBE) Statement: Guidelines for reporting observational studies. Int J Surg. 2014;12(12):1495-9.

13. Leino K, Mildh L, Lertola K, Seppälä T, Kirvela O. Time course of changes in breathing pattern in morphine and oxycodone-induced respiratory depression. Anaesthesia. 1999;54:835-40.

14. Rose DK, Cohen MM, Wigglesworth DF, DeBoer DP. Critical respiratory events in the postanesthesia care unit. Patients, surgical, and anesthetic factors. Anesthesiology. 1994;81:410-8.

15. Stewart PA, Liang SS, Li QS, Huang ML, Bilgin AB, Kim D, et al. The impact of residual neuromuscular blockade, oversedation, and hypothermia on 
adverse respiratory events in a postanesthetic care unit: a prospective study of prevalence, predictors, and outcomes. Anesth Analg. 2016;123(4):859-68.

16. McCarter T, Shaik Z, Scarfo K, Thompson LJ. Capnography monitoring enhances safety of postoperative patient-controlled analgesia. Am Health Drug Benefits. 2008;1:28-35.

17. Kaur R, Vines $D L$, Liu L, Balk RA. Role of integrated pulmonary index in identifying extubation failure. Respir Care. 2017;62:1550-56.

18. Kadam VR, Danesh M. Post operative capnostream monitoring in patients with obstructive sleep apnoea symptoms - Case series. Sleep Sci. 2016;9(3):142-46.

\section{Publisher's Note}

Springer Nature remains neutral with regard to jurisdictional claims in published maps and institutional affiliations.

Ready to submit your research? Choose BMC and benefit from:

- fast, convenient online submission

- thorough peer review by experienced researchers in your field

- rapid publication on acceptance

- support for research data, including large and complex data types

- gold Open Access which fosters wider collaboration and increased citations

- maximum visibility for your research: over $100 \mathrm{M}$ website views per year

At BMC, research is always in progress.

Learn more biomedcentral.com/submissions 